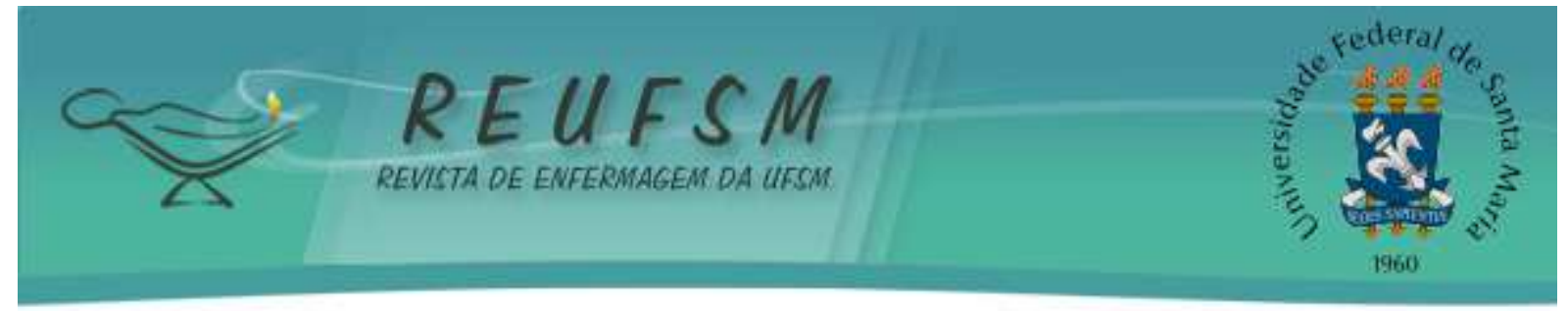

ARTIGO ORIGINAL

\title{
MÉTODO CANGURU: BENEFÍCIOS E DESAFIOS EXPERIENCIADOS POR PROFISSIONAIS DE SAÚDE
}

\section{KANGAROO CARE METHOD: BENEFITS AND CHALLENGES EXPERIENCED BY HEALTH PROFESSIONALS}

MÉTODO CANGURO: BENEFICIOS Y DESAFÍOS EXPERIMENTADOS POR PROFESIONALES DE LA SALUD

\author{
Elaine Cristina Rodrigues Gesteira ${ }^{1}$ \\ Patrícia Pinto Braga² \\ Marina Nagata ${ }^{3}$ \\ Luiza Ferreira Cantão dos Santos ${ }^{4}$ \\ Camila Hobl ${ }^{5}$ \\ Bárbara Gomes Ribeiro ${ }^{6}$
}

Doi: $10.5902 / 2179769220524$

RESUMO: Objetivo: conhecer os benefícios e os desafios experienciados por profissionais de saúde acerca do método canguru. Método: pesquisa exploratória, descritiva, de natureza qualitativa, que utilizou a Teoria das Representações Sociais e como método de análise o Discurso do Sujeito Coletivo com 22 profissionais de saúde de um Centro de Terapia Intensiva Neonatal e Pediátrica por meio de entrevistas semiestruturadas realizadas no período de novembro e dezembro de 2012. Resultados: emergiram oito discursos do sujeito coletivo, sendo que quatro sinalizaram os benefícios do método para o recém-nascido e família, os demais apontaram os desafios encontrados na experiência do método. Conclusão: adequações na estrutura física, aprimoramento de recursos humanos e comprometimento dos gestores são aspectos-chave para a consolidação do Método Canguru. Este estudo poderá contribuir nas reflexões de profissionais de saúde, entre eles, os da enfermagem, visando a melhoria de suas práticas assistenciais.

Descritores: Método canguru; Prematuro; Terapia intensiva neonatal; Humanização da assistência.

Aim: to know the benefits and challenges experienced by health professionals in relation to the kangaroo care method. Method: exploratory, descriptive and of a qualitative nature study that used the Social Representation Theory, and the Collective Subject's Speech as an analytical method. It was carried out with 22 health professionals from a Neonatal and Pediatric Intensive Care Unit through semi-structured interviews held during the period of November and December 2012. Results: eight speeches of the collective subject emerged, four signaled the benefits of the method to the newborn and to the

\footnotetext{
1 Enfermeira. Doutoranda em Ciências pela EEUSP. Professora Adjunta do Curso de Enfermagem da Universidade Federal de São João del Rei. Divinópolis, MG, Brasil. E-mail: ecr.gesteira@hotmail.com

2 Enfermeira. Doutora em Enfermagem pela EEUFMG. Professora Adjunta do Curso de Enfermagem da Universidade Federal de São João del Rei. Divinópolis, MG, Brasil. E-mail: patriciabraga@gmail.com

3 Enfermeira graduada pela Universidade Federal de São João del Rei. Divinópolis, MG, Brasil. E-mail: marina_nagata8@hotmail.com

4 Enfermeira graduada pela Universidade Federal de São João del Rei. Divinópolis, MG, Brasil. E-mail: lulucantao@hotmail.com

5 Enfermeira graduada pela Universidade Federal de São João del Rei. Divinópolis, MG, Brasil. E-mail: camila.hobl@yahoo.com.br

${ }^{6}$ Enfermeira graduada pela Universidade Federal de São João del Rei. Divinópolis, MG, Brasil. E-mail: barbaragomesribeiro@gmail.com
} 


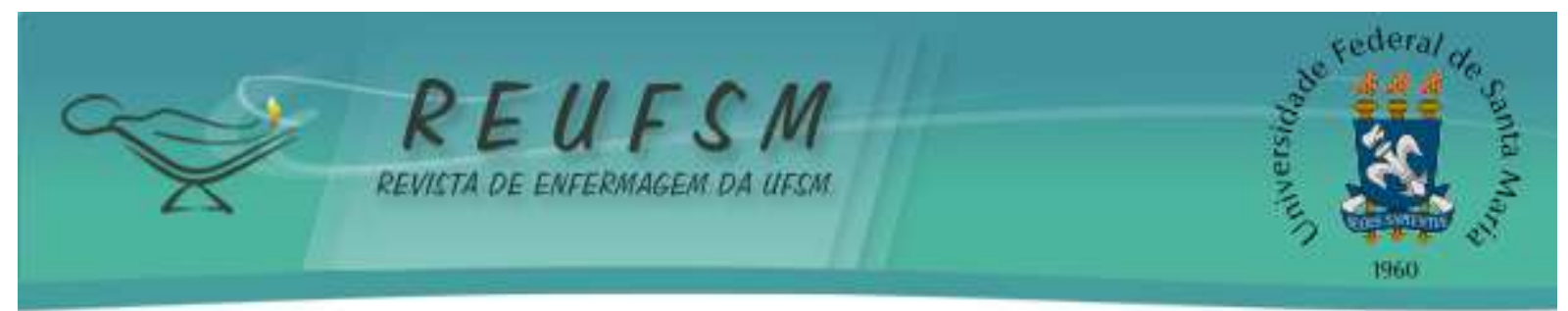

family, while the others showed the challenges encountered from the experience of the method. Conclusion: adjustments in the physical structure, improvement of human resources and commitment of the managers are key aspects for the consolidation of the method. This study may contribute to health professional insights, including the nursing order to improve their care practices.

Descriptors: Kangaroo-mother care Method; Premature; Intensive care neonatal; Humanization of assistance.

RESUMEN: Objetivo: conocer los beneficios y desafíos experimentados por profesionales de la salud sobre el método canguro. Método: investigación exploratoria, descriptiva, de naturaleza cualitativa, que utilizó la Teoría de las Representaciones Sociales, y como un método de análisis el Discurso del Sujeto Colectivo, con 22 profesionales de la salud de una Unidad de Cuidados Intensivos Neonatales y Pediátricos por medio de entrevistas semiestructuradas en el período entre noviembre y diciembre de 2012. Resultados: surgieron ocho discursos del sujeto colectivo, cuatro señalaron los beneficios del método para el recién nacido y la familia, los otros mostraron los desafíos encontrados en la experiencia del método. Conclusión: las adecuaciones en la infraestructura física, el perfeccionamiento de los recursos humanos y el comprometimiento de los gestores son aspectos clave para la consolidación del método. Este estudio puede contribuir con las reflexiones de los profesionales de salud, en especial, con los de enfermería, con el objetivo de mejorar sus prácticas de atención.

Descriptores: Método madre-canguro; Prematuro; Cuidado intensivo neonatal; Humanización de la atención.

\section{INTRODUÇÃO}

Mundialmente, segundo dados da Organização Mundial de Saúde, ${ }^{1}$ nascem por ano, cerca de 15 milhões de recém-nascidos (RN) prematuros, sendo que no Brasil o número de partos prematuros, antes da trigésima sétima semana de gestação, é de 9,2\%; assim emerge no cenário contemporâneo um número significativo de crianças prematuras que necessitam de cuidados hospitalares prolongados em Unidades de Terapia Intensiva Neonatais (UTINs). ${ }^{2}$

Nesse sentido, no âmbito da assistência ao RN, um dos aspectos centrais da necessidade de reconfiguração da atenção neonatal tem sido a tentativa de rompimento com uma prática assistencial que se apodera da vida dos neonatos sem compartilhar com a família as decisões vitais inerentes ao tratamento da criança. ${ }^{2-3}$

Nesta perspectiva de inserir a família no cuidado ao RN, criando um novo modelo assistencial, o Método Canguru (MC), proposto pelo Ministério da Saúde ${ }^{2}$ desde o ano 2000, vem favorecer mudanças paradigmáticas na atenção perinatal, ${ }^{4}$ ou seja, um modelo de assistência a ser seguido pelas instituições de saúde e que tem como principal eixo o protagonismo materno, bem como de toda a família.

Historicamente, o cuidado canguru teve sua origem na Colômbia, em 1979, e surgiu com uma proposta de melhoria no cuidado aos Recém-Nascidos Pré-Termos - RNPT. No Brasil, as primeiras iniciativas aconteceram na década de 90 por meio da iniciativa de maternidades como o Hospital Guilherme Álvaro em Santos-SP e o Instituto de Medicina Integral Professor Fernando Figueira em Pernambuco e, em seguida, difundiu-se rapidamente pelo país.

No ano 2000 foi promulgada a Portaria MS/GM 693, que publicou a Norma de Atenção Humanizada ao RN de baixo peso, com o objetivo de inserir o método como uma estratégia 


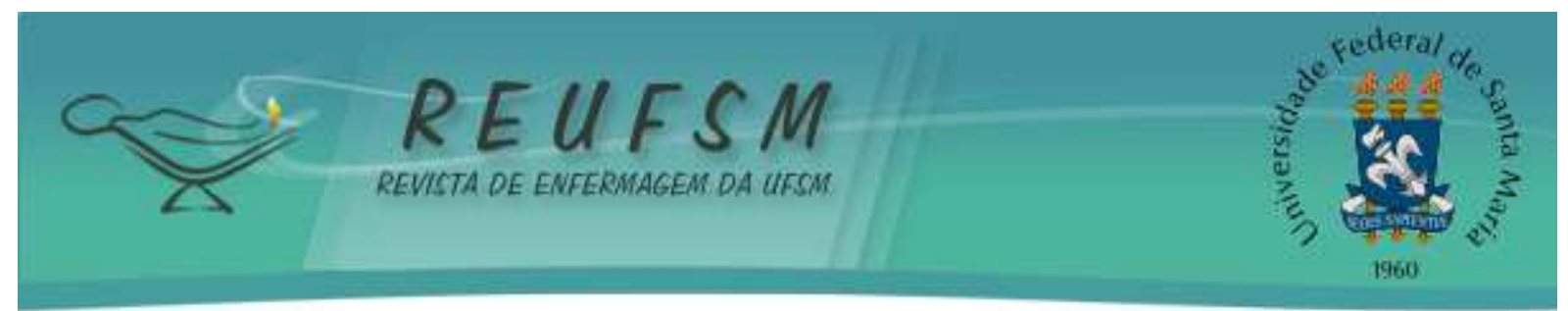

de humanização à assistência ao RN de baixo peso e incentivar uma mudança no perfil profissional. $^{2}$

Esse modelo de cuidado se baseia em princípios que envolvem o acolhimento do RN e de sua família na UTIN, respeito às singularidades do RN e família, promoção do contato pele a pele, incentivo aos pais para cuidarem do RN no universo da UTI e diretrizes para a continuidade do cuidado. Entre os benefícios do método, destacam-se a promoção do aleitamento materno, a manutenção do controle térmico e redução da dor neonatal. Essa proposta de cuidado tem se mostrado favorável por permitir um maior estímulo no desenvolvimento neurocomportamental e psicoafetivo do $\mathrm{RN}$ e, sobretudo, na redução do período de internação e de risco de infecção neonatal. ${ }^{2}$

Tecnicamente, o método é composto por três etapas e consiste no contato pele a pele do RN de baixo peso, na posição supina entre os seios dos pais ou outros familiares. A primeira etapa tem início no pré-natal de alto risco e ocorre até a alta do RN da UTIN, tem como objetivo promover o contato com a família sempre que possível, estimulando livre acesso na Unidade Neonatal. A segunda etapa consiste em um estágio pré-alta hospitalar, em que a família realiza cuidados ao seu filho e o contato pele a pele, já a terceira ocorre com o acompanhamento da criança no ambulatório ou domicílio até que ele alcance o peso de 2500 gramas. $^{5}$

Dentre as medidas que favorecem a efetividade do método, destacam-se a capacitação contínua da equipe multiprofissional, para atender desde o pré-natal às gestantes de risco e estruturas hospitalares que favoreçam a participação da família, incluindo o acesso sem restrições de todos os membros familiares. Além disso, medidas que possam adequar o ambiente da UTIN, como diminuição da luminosidade em alguns períodos, manipulação mínima do $\mathrm{RN}$, controle da dor neonatal, redução de ruídos, encorajamento do aleitamento materno e comunicação efetiva de acordo com a compreensão dos familiares, que garantam um cuidado humanizado no atendimento ao RN e sua família, princípio norteador deste modelo assistencial. ${ }^{2}$

Neste sentido, um estudo brasileiro ${ }^{4}$ avaliou a implantação e condução do $M C$ em maternidades de alto risco, as quais promoveram capacitações aos funcionários, preparando-os para este modelo de assistência, e identificaram que alguns hospitais maternidades não possuíam local adequado para permanência dos pais durante a internação dos filhos na unidade. Este achado se revelou como desfavorável ao método porque fragmenta o tempo de permanência da família na UTIN.

Diante do exposto, emergiu a seguinte questão norteadora: quais são as percepções dos profissionais de saúde acerca do Método Canguru e os desafios experienciados na sua implementação?

0 interesse pelo estudo se justifica pela importância do $M C$ na reconfiguração do modelo de atenção neonatal e as possíveis dificuldades de implementação sob a ótica dos profissionais de saúde que a vivenciam na Unidade Neonatal.

Assim, o objetivo do estudo foi conhecer os benefícios e os desafios experienciados por profissionais de saúde acerca do Método Canguru.

\section{MÉTODO}

Estudo de caráter exploratório, descritivo e de natureza qualitativa. O método qualitativo de pesquisa permite adentrar o universo desconhecido e compreendê-lo a partir da visão dos participantes acerca de um fenômeno. ${ }^{6}$

Para conhecer as percepções de um grupo social, neste caso, dos profissionais de saúde que atuam no MC, utilizou-se a Teoria das Representações Sociais (TRS), teoria que busca apreender as atitudes e comportamentos de um grupo em face a um objeto comum 


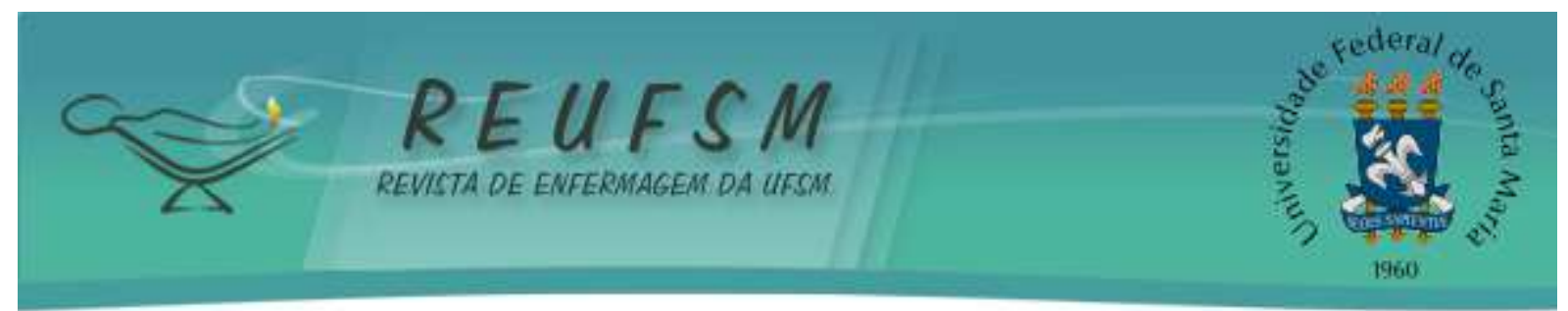

a todos. ${ }^{7-8}$ Assim, conhecendo a prática deste grupo de profissionais, é possível suscitar reflexões sobre o $M C$ e os seus desafios.

0 estudo foi desenvolvido no Centro de Terapia Intensiva Neonatal e Pediátrica (CTINP) de um hospital do Centro-Oeste de Minas Gerais, o qual é referência para 57 municípios dessa região mineira. Esta unidade é composta por 45 profissionais assim distribuídos: 14 técnicos de enfermagem, dois auxiliares de enfermagem, seis enfermeiros assistenciais, quatro enfermeiros clínicos-supervisores, uma coordenadora de enfermagem, um responsável técnico médico, nove médicos pediatras plantonistas, sendo um neonatologista e oito pediatras, cinco fisioterapeutas, uma secretária e dois profissionais da limpeza. Conta também com o apoio da psicologia e serviço social. Todos os profissionais foram convidados a participarem do estudo, pois a intenção dos pesquisadores era de entrevistar aqueles que experienciavam a implementação do método.

Destes, 22 aceitaram participar do estudo mediante assinatura do Termo de Consentimento Livre e Esclarecido, sendo dois médicos (um neonatologista e um pediatra), quatro fisioterapeutas, cinco enfermeiros (uma coordenadora, dois supervisores, dois assistenciais), nove técnicos de enfermagem e dois auxiliares de enfermagem. Utilizou-se como critério de inclusão desse estudo abranger as distintas categorias profissionais de saúde com participação direta ou indireta no método canguru há mais de um mês, e mediante a sua aceitação em participar da entrevista. Foram excluídos os profissionais que não realizam o MC. Esta unidade foi inaugurada em 1999, e em 2010 os profissionais de saúde foram capacitados para o desenvolvimento do MC. Até esta data, algumas práticas isoladas aconteciam, mas ainda se precisava de uma estrutura interna favorável para que os familiares pudessem se acomodar na posição recomendada para a realização do MC. As capacitações conforme o manual do MC aconteceram entre os anos de 2011 a 2012.

Para a realização da coleta de dados, utilizou-se a entrevista semiestruturada composta pelas seguintes questões norteadoras: como você define o MC? Fale sobre sua experiência no MC do CTINP/ Descreva os desafios experienciados na implementação do método no CTINP. A coleta de dados ocorreu durante os meses de novembro e dezembro de 2012. As entrevistas foram gravadas por meio de um gravador digital e ocorreram em uma sala privativa dentro do CTINP, onde se manteve o sigilo e privacidade dos entrevistados.

Para análise do material empírico, utilizou-se o Discurso do Sujeito Coletivo (DSC), uma técnica de tabulação e de organização dos dados qualitativos fundamentada nos pressupostos da Teoria da Representação Social, que tem como matriz filosófica elementos da Sociologia. ${ }^{9}$

O DSC busca extrair as representações sociais oriundas de dados empíricos, ou seja, a partir dos discursos dos participantes. Esse método de análise busca não reduzir os discursos a categorias, mas propicia a transparência de um conjunto de representações sociais, ${ }^{9}$ neste caso, de opiniões dos profissionais de saúde, que retratam a representação desta coletividade que vivencia a implementação do MC.

A partir do material produzido, foram identificadas as ideias centrais e expressõeschave sobre a temática, os dados que tinham semelhança foram agrupados em discursos, em primeira pessoa, caracterizando as opiniões dos profissionais de saúde.

Esta pesquisa cumpriu as exigências éticas descritas na Resolução $n^{\circ}$. 466/2012, do Conselho Nacional de Saúde e foi aprovada pelo Comitê de Ética em Pesquisa da Universidade Federal de São João Del Rei-Campus Divinópolis-MG sob o Parecer de número 128.464, em 07/11/2012. 


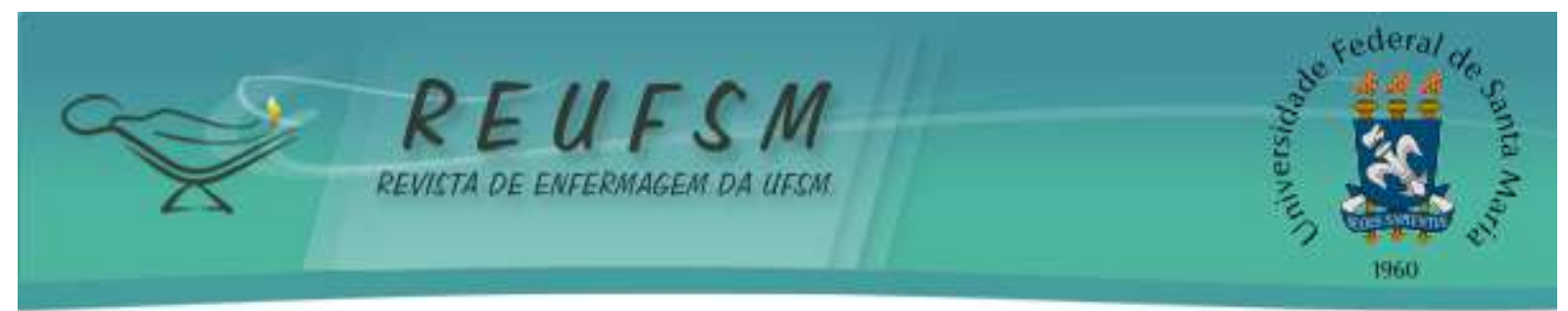

\section{RESULTADOS E DISCUSSÃO}

A análise do material revelou os benefícios e desafios experienciados pelos profissionais de saúde do CTINP sobre o MC. Os resultados identificados em oito ideias centrais permitiram construir quatro Discursos do Sujeito Coletivo, que revelaram os benefícios do método, a saber: a tranquilidade do RN, melhora e recuperação do RN, interação com os membros familiares através do contato precoce com o RN, e aleitamento materno (DSC 1, 2, 3 e 4). A análise revelou, também, outros quatro discursos (DSC 5, 6, 7 e 8) que apontaram os desafios para a implementação, identificados pela insegurança da família na realização do $M C$, insegurança e falta de conhecimento da equipe de trabalho, ausência de educação permanente para estes profissionais e falta de normatização para a aplicabilidade do método.

$\mathrm{Na}$ experiência dos profissionais, o MC favorece uma mudança comportamental dos neonatos, que demonstram maior serenidade e tranquilidade no momento da vivência canguru (DSC 1). Os profissionais entrevistados enfatizam que há mudanças positivas no recém-nascido, como a estabilidade das funções fisiológicas e a aproximação promovida pelo contato do RN com a família, como pode ser constatado nos discursos (DSC 2 e DSC 3) a seguir:

as crianças que participam do método canguru ficam mais calmas, mais tranquilas. A agitação neuropsicomotora também é reduzida com esse contato pele a pele. Os bebês gostam muito dessa posição. Então, pra mim é um método bom, que apresenta eficácia, que a gente pode perceber o tanto que o recém-nascido fica calmo no calor da mãe e do pai. (DSC 1-Tranquilidade do Recém-Nascido)

é visível a melhora dos pacientes [..]. As crianças que participam tem mais facilidade de sair do oxigênio, mais facilidade do controle motor, do controle de sucção, ela consegue observar mais o que está em volta dela. É um método não farmacológico de alívio da dor da criança [...]. Além disso, a criança sente o afeto e carinho dos pais, se recuperam mais rápido e, com isso, o índice de alta é maior na UTI. (DSC 2- Melhora e Recuperação do RN)

o MC proporciona a entrada precoce dos pais dentro da Unidade, a participação deles no tratamento da criança. A mãe fica bem, até se emociona [...] com a satisfação de estar pegando aquele bebê. Aumenta também o vínculo dos pais, os homens, principalmente, que, às vezes, tem muito medo, quando eles veem a mãe fazendo eles querem fazer também, então interage a família. O método é a presença da mãe mais perto do filho, como a incubadora separa, é a junção. É reencontro. É carinho. É amor. (DSC 3- Interação da família através do contato precoce com o RN)

Nesse contexto, estudo realizado ${ }^{10}$ com o objetivo de conhecer a percepção de puérperas acerca da realização do $M C$ demonstrou que elas percebiam em seus bebês uma melhora no sono, tranquilidade e segurança durante o cuidado canguru. Os resultados desta investigação apontam que o $M C$ tem como uma de suas vantagens a redução no estresse do neonato, o que é observado nos relatos dos profissionais presentes no DSC 1 e DSC 2. 


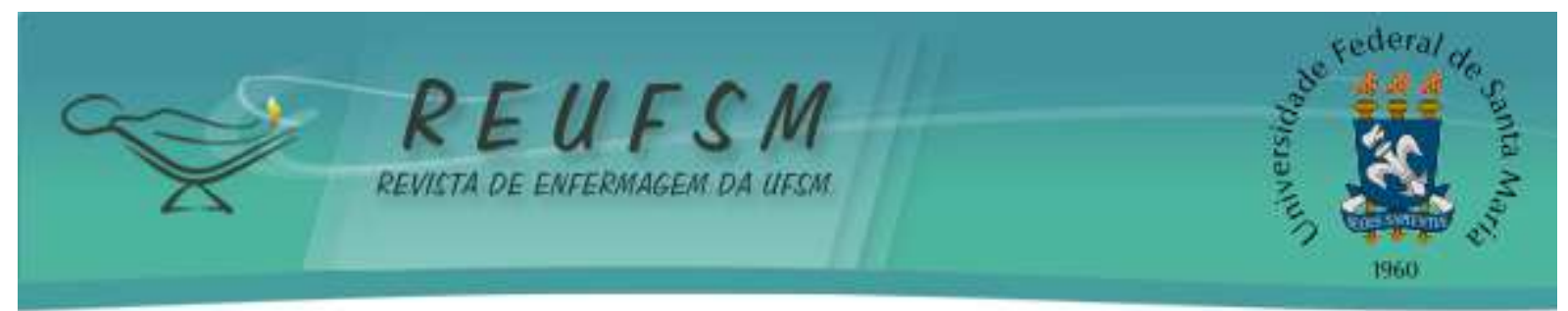

Nesses discursos, os profissionais participantes também reconheceram que o método pode ser considerado um suporte não farmacológico para alívio da dor, uma estratégia que favorece o desenvolvimento neuropsicomotor e fisiológico do bebê, e a evolução do seu quadro clínico.

Em suma, os avanços adquiridos com o programa MC apontam uma melhora da instabilidade clínica, os bebês se acalmam, diminuindo o nível de estresse e o choro em resposta à dor. ${ }^{11-12}$ Neste âmbito, o contato precoce, proposto pelo MC, dos familiares com o RNPT durante a internação contribui de forma significativa para a melhora dos bebês, assim como explicitado no DSC 3, em que são citados como benefícios o aumento do vínculo entre prematuro e família, diminuição no tempo de separação entre a mãe e o bebê, da sala de parto até a UTIN, além do fortalecimento com as equipes responsáveis pelos cuidados. ${ }^{2}$

O relacionamento afetivo da família com o filho contribui para a formação da identidade materna/paterna, favorecendo o cuidado apropriado com o recém-nascido e uma aproximação psicoafetiva de satisfação e conexão mãe e bebê. ${ }^{13-14}$

Diante dos relatos, é notável que os profissionais de saúde reconhecem que o MC apresenta vantagens que facilitam a recuperação dos RNs prematuros e de baixo peso. materno.

O DSC 4, apresentado a seguir, revela que o MC favorece o estímulo ao aleitamento

As vantagens são inúmeras, fisiológicas, de conforto. Acho que influencia em relação ao leite materno também. $O$ método estimula a descida do leite, estimula a criança, a sucção. Aumenta a chance da mãe amamentar, porque a criança tem o contato próximo ao seio. (DSC 4 -Aleitamento Materno)

Assim como consta no relato dos profissionais ao citar como vantagem do MC o estímulo à descida do leite, sabe-se que a posição canguru permite a interação mãe-filho. Esse fator auxilia na ejeção do leite devido ao fortalecimento do estado emocional da mãe, além de contribuir para o desenvolvimento do reflexo de busca pela proximidade que o bebê tem ao seio materno, permitindo maior frequência e duração das mamadas. ${ }^{14}$

O MC vem sendo adotado como uma das principais estratégias para promoção do aleitamento materno em recém-nascidos pré-termos e de baixo peso, tendo sua eficácia comprovada em estudos, ${ }^{14-15}$ nos quais a incidência de aleitamento materno exclusivo foi consideravelmente maior nos RNPT que participaram do método, até mesmo após seis meses da alta hospitalar.

Essas pesquisas mostram que o Ministério da Saúde ${ }^{5}$ está alcançando a sua meta em relação ao aleitamento materno por meio de orientações às equipes que atuam em Maternidades e Unidades Neonatais. As mães que participam do MC estão sendo informadas e estimuladas à amamentação exclusiva do RNPT e de baixo peso, o que contribui para a melhoria da assistência neonatal.

Os DSCs 5, 6, 7 e 8 apresentam os desafios existentes para a implementação e prática do MC. A Insegurança da família na realização do método (DSC 5) revela o receio dos familiares nos contatos iniciais com seus bebês, como descrito a seguir:

um desafio do método canguru é o medo e receio dos pais em pegar a criança no colo. Nos primeiros contatos da família com a criança, por ter muito aparelho ligado, a mãe ainda fica insegura. Eles têm medo por serem crianças pequenas, prematuras e frágeis. $A$ insegurança que eles desenvolvem nesse primeiro contato é devido 


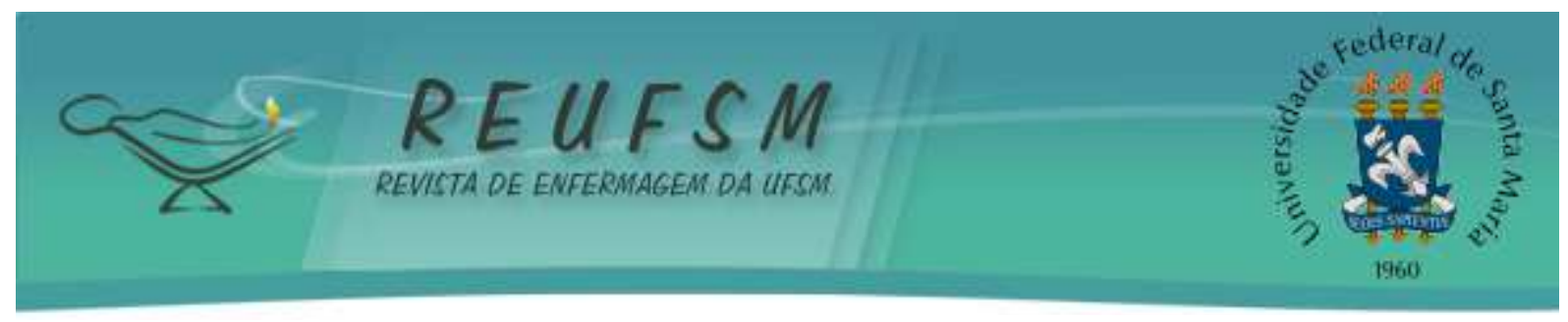

ao pouco conhecimento dos familiares em relação a essa possibilidade de cuidado. (DSC5- Insegurança dos pais na realização do $M C$ )

Percebe-se, por meio das falas dos profissionais, o relato sobre o medo e a insegurança dos pais e familiares em relação ao contato com o bebê como um dos desafios em se implementar o MC. Na visão dos profissionais, essa insegurança da família está relacionada com a interrupção da gravidez e consequente nascimento do filho prematuro, que possui características físicas e neurológicas que demandam cuidados mais específicos. ${ }^{16-17}$

Para a mãe que esperava por um bebê saudável e com o nascimento na época prevista, ter um filho prematuro e de baixo peso que necessita de cuidados especializados é uma situação nova e ameaçadora. A família apresenta um luto pela perda do bebê imaginado e, ainda, angústia com o que ocorrerá a partir deste momento. ${ }^{18}$

Ao entrar na UTIN a família sente tristeza, dúvidas e incertezas em face ao cuidado com o filho, e enfrenta dificuldades não somente pelas características específicas do prematuro mas também pela presença de aparelhos e procedimentos realizados com o seu bebê. ${ }^{19}$ Para minimizar este sofrimento, é importante estimular os pais na formação do vínculo com a criança, no contato pele a pele; ela precisa ser tocada, pois é a partir do toque que o bebê inicialmente interage com o outro. Para os pais que chegam na UTIN, faz-se importante esta intervenção, pois sentem medo de tocar os seus filhos. Por este motivo, precisam ser encorajados pela equipe de saúde, especialmente a enfermagem, que por excelência cuida, tendo um contato para a realização de diversos procedimentos no decorrer do plantão com a criança e família.

Nesse aspecto, o modelo assistencial do MC veio contribuir para que os aspectos psicoafetivos entre a família e o RN fossem respeitados, e também alavancar o debate sobre a adequação das instituições para atender esta demanda, ou seja, o preparo da equipe e da unidade para atender a esta política de humanização. ${ }^{20}$

Vale ressaltar que a família dos RNs de baixo peso sente medo e receio em cuidar dos seus filhos. Desse modo, os profissionais de saúde necessitam de uma educação permanente para a ampliação do conhecimento sobre os benefícios do MC. A partir dessa educação permanente e sensibilização da equipe, eles poderão fornecer informações mais precisas e seguras aos familiares no cuidado com os seus bebês. ${ }^{21}$

O DSC 6- Insegurança e falta de conhecimento e aprimoramento dos profissionais, reafirma a ideia de educação permanente, como descrito a seguir:

às vezes te dá uma insegurança, pegar o prematurinho [...], super delicado e colocar ali. Tem momentos que a gente se sente inseguro de pegar uma criança que está mais grave, está mais instável, de tá colocando no colo e ela desestabilizar. O problema ainda é o profissional não querer mesmo implantar, às vezes porque atrasa o serviço, pois atrasa bastante o serviço. Além disso, existe falta de treinamento da equipe. (DSC 6 - Insegurança e falta de educação permanente)

Os entrevistados revelam insegurança ao manipularem o RN prematuro e falta de entendimento sobre o método, levando-os à crença de que os procedimentos a serem executados no RN são impossibilitados porque a criança está em MC.

Esses apontamentos dos entrevistados revelam a falta de conhecimento que possuem sobre o impacto do $M C$ na vida do RNs e de suas famílias, e a não percepção de 


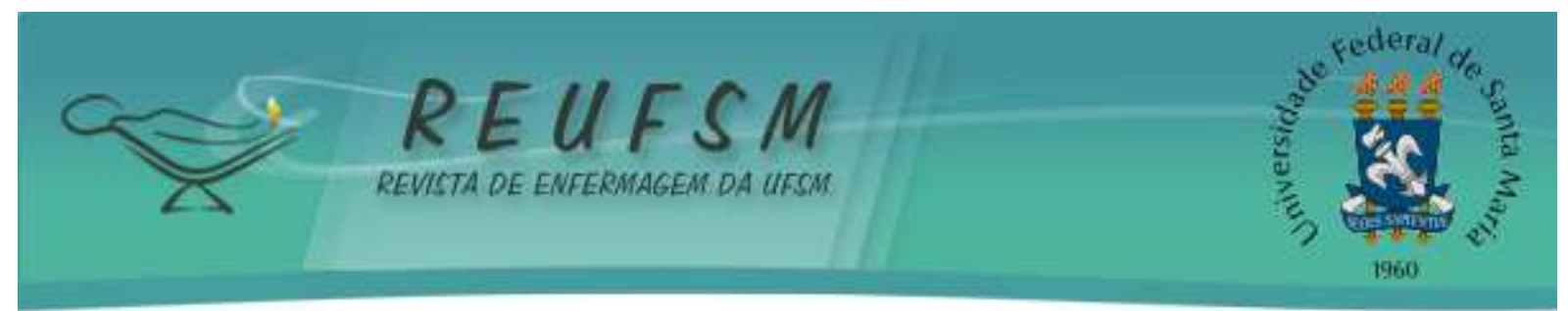

que as vantagens do método superam os desafios que estes julgam existir. Estes achados revelam que estratégias de educação permanente acerca do método precisam ser intensificadas. $^{10}$

Em um estudo, ${ }^{21}$ menciona-se que é preciso pensar em espaços que possam favorecer a discussão e a interação entre o maior número de profissionais e familiares, ou seja, promover uma melhor comunicação entre profissionais e família continuamente, a fim de que juntos possam alcançar a efetivação do $M C$ na unidade. Esse espaço de discussão aumentaria a segurança no manejo do $M C$, principalmente daqueles que estão mais próximos desse processo, incluindo médicos, enfermeiros, técnicos de enfermagem, fisioterapeutas, fonoaudiólogos, entre outros.

Salienta-se ainda que, para atingir a eficácia na implementação do método, precisa-se elaborar, primeiramente, normas e rotinas dos setores envolvidos, desde o setor de recepção até a UTIN, para depois estabelecer os programas de treinamento e avaliação profissional da unidade estudada, conforme preconiza o Manual do MC. ${ }^{2}$ Além disso, adequações na estrutura física da UTIN são necessárias para acomodar melhor os familiares no setor, e também a escolha de um profissional coordenador que auxilie no levantamento das necessidades do local para sugestão de melhorias.

Nesse ínterim, os DSCs 7 e 8 salientam que mesmo após participarem da educação permanente, inicialmente realizada para a implementação do $M C$ na unidade, eles necessitam da continuidade desses encontros de educação permanente, para que possam favorecer a revisão da Norma de Atenção Humanizada ao Recém-Nascido, estabelecida pelo Ministério da Saúde. ${ }^{5}$

Um desafio é a gente conseguir realmente definir qual criança vai para o cuidado canguru, qual ainda não vai e os critérios a serem adotados. Algumas instituições colocam as crianças entubadas no CPAP, outras já são mais restritas e acho que a definição dos critérios e o treinamento da equipe são os principais desafios. Aqui, a criança entubada dificilmente realiza o método. É realizado só quando está com cateter nasal ou ar ambiente. (DSC 7-Falta de normatização para aplicabilidade do MC)

Uma dificuldade é realmente enquadrar o MC conforme o Ministério da Saúde preconiza. E um canguru com menos de 40 minutos não é eficaz, a criança terá só o trabalho e desconforto de sair da incubadora e ir para o colo e depois de sair do colo e voltar para incubadora. Outro desafio é a falta de informação, a partir do momento que se tem a informação, acho que melhora para ambas as partes. (DSC 8 - Fragilidade do profissional acerca do conhecimento sobre o MC)

Em meados da década de 80, o MC passou a ser amplamente divulgado pelo Fundo das Nações Unidas para a Infância (UNICEF), o que impulsionou hospitais brasileiros a adotarem a prática da posição canguru para a população de mães e bebês pré-termo. Contudo, o método passou a ocorrer de forma não sistematizada e sem critérios técnicos bem definidos. ${ }^{2}$

A história pessoal de cada profissional e as condições de cada instituição influenciam na organização do MC, por isso, a normatização estabelecida pelo Ministério da Saúde nem sempre é seguida na política da instituição. Em outras palavras, é difícil 


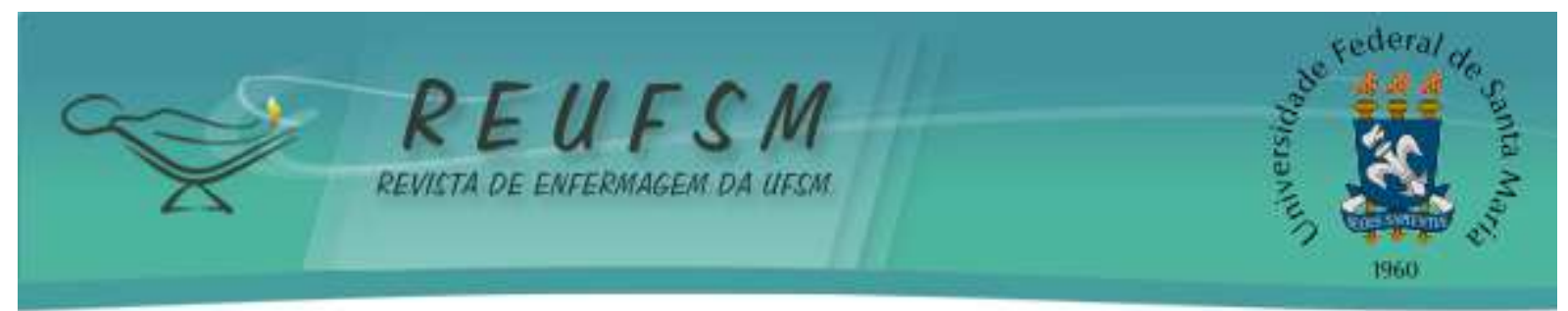

implementar o método se não houver um conhecimento e comprometimento institucional e profissional, como visto na representação dos discursos destes participantes. ${ }^{22}$

É necessário que as maternidades de alto risco possam analisar o ambiente que se tem e adequá-lo para a execução do método, sensibilizando profissionais e estabelecendo metas que deem escuta aos envolvidos, de modo a avaliar a assistência e melhorá-la em prol dos RNs e suas famílias.

Neste estudo, os benefícios e desafios percebidos pelos profissionais corroboram com os demais achados da literatura, que envolvem a temática na perspectiva da equipe de saúde. Reforça-se a contribuição para futuras reflexões de gestores e profissionais que desejam ou estão experienciando o processo de implementação do MC em suas respectivas instituições.

\section{CONSIDERAÇÕES FINAIS}

Considera-se, nesta investigação, que os profissionais de saúde conhecem a importância e mencionam as vantagens do MC. Porém, reconhecem que os desafios existentes são diversos, não somente relacionados à estrutura física do CTINP, mas, sobretudo, diante da necessidade de aprimoramento para que se sintam mais seguros e executem o MC com eficácia.

Acredita-se que adequações na estrutura física, como propiciar um local reservado para que os pais possam participar do MC e ter momentos para o diálogo com a equipe multiprofissional, e ainda recursos humanos que incluam não somente os profissionais da saúde, mas também a interação efetiva do serviço de nutrição, serviço social, fonoaudiologia e psicologia, são necessárias para o sucesso da implantação.

Além disso, é preciso um maior comprometimento dos gestores para que a Norma de Atenção Humanizada seja cumprida, visto que neste estudo os DSCs apontam para uma desorganização da implantação, focada e restrita ao ambiente da UTIN, sem considerar os outros profissionais que atuam em outros serviços da maternidade. Nota-se que as representações dos discursos se restringem à falta de um protocolo, ou ainda a normas e rotinas para o setor, com base no Ministério da Saúde, que norteiam a execução do $M C$.

Sugerem-se novos estudos que abordem os temas do MC durante a educação permanente dos participantes envolvidos neste estudo e a reformulação de normas e rotinas que sinalizem a reelaboração, organização e efetivação deste modelo assistencial.

A limitação deste estudo está relacionada a não permitir generalização dos resultados, apenas mostrando a representação de um grupo sobre este tema em um determinado cenário.

\section{REFERÊNCIAS}

1. World Health Organization (WHO), March of Dimes, PMNCH, Save the Children. Born too soon: the global action report on preterm birth [INternet]. Howson CP, Kinney MV, Lawn JE, editors. Geneva: WHO; 2012. Disponivel em: http://apps.who.int/iris/bitstream/10665/44864/1/9789241503433_eng.pdf.

2. Brasil. Ministério da Saúde. Secretaria de Atenção a Saúde. Departamento de Ações Programáticas Estratégicas. Atenção humanizada ao recém-nascido de baixo peso: método Canguru: manual técnico. Brasília: Ministério da Saúde; 2013.

3. Braga $P$, Sena RR. Cuidado e diálogo: as interações e a integralidade no cotidiano da assistência neonatal. Rev Rene. 2010;11(N Esp):142-9. 


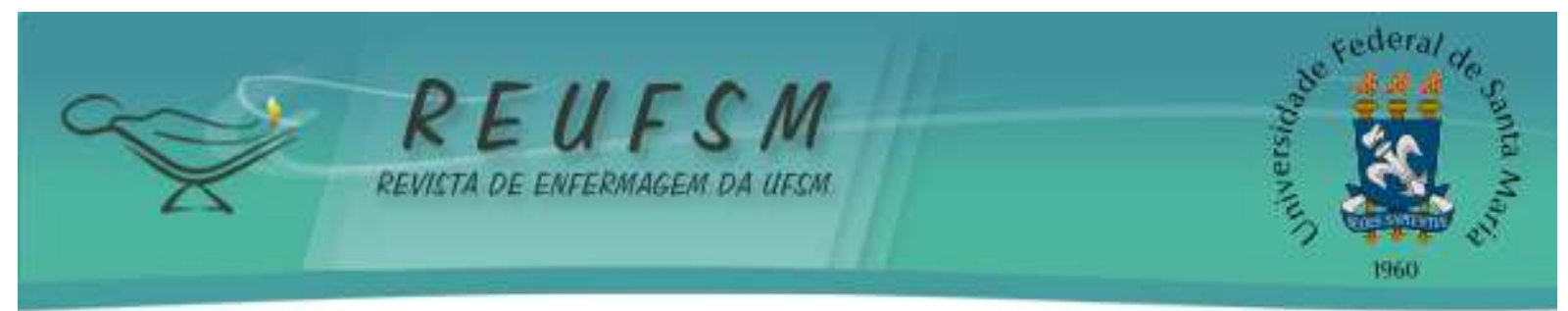

4. Gontijo TL, Meireles AL, Malta DC, Proietti FA, Xavier CC. Evaluation of implementation of humanized care to low weight newborns: the Kangaroo Method. J Pediatr. 2010;86(1):33-9.

5. Brasil. Ministério da Saúde. Secretaria de Atenção à Saúde. Relatório sobre o Método Canguru desde sua implantação até os dias atuais, com critério para prosseguimento e expansão do projeto, incluindo a capacitação de recursos humanos. Brasília: Ministério da Saúde; 2009.

6. Minayo MC. Análise qualitativa: teoria, passos e fidedignidade. Cienc Saúde Colet. 2012;17(3):621-6.

7. Arruda A. Pesquisa em representações sociais: a produção em 2003. In. Menin MSDS, Shimizu AM, organizadoras. Experiências e representação social: questões teóricas e metodológicas. São Paulo: Casa do Psicólogo; 2005.

8. Silva SED, Camargo BV, Padilha MI. A teoria das representações sociais nas pesquisas da enfermagem brasileira. Rev Bras Enferm. 2011,64(5):947-51.

9. Lefèvre F, Lefèvre AMC. Discurso do sujeito coletivo: representações sociais e intervenções comunicativas. Texto \& Contexto Enferm. 2014;23(2):502-7.

10. Neves PN, Ravelli APX, Lemos JRD. Atenção humanizada ao recém-nascido de baixopeso (método Mãe Canguru): percepções de puérperas. Rev Gaúcha Enferm [Internet]. 2010 mar [acesso em 2015 jun 20];31(1):48-54. Disponível em: http: / /www.scielo.br/scielo.php?script=sci_arttext\&pid=S1983-

14472010000100007\&lng=en.http://dx.doi.org/10.1590/S1983-14472010000100007.

11. Moore ER, Anderson GC, Bergman N, Dowswell T. Early skin-to-skin contact for mother and their healthy newborn infants. Europe PMC Funders Group, Cochrane Database Syst Rev [Internet]. 2012 mar [acesso em 2015 abr 19];10(0):1-15. Disponível em: https://www.ncbi.nlm.nih.gov/pmc/articles/PMC3979156/pdf/emss-57256.pdf.

12. Maia FA, Azevedo VMGO, Gontijo FO. Os efeitos da posição canguru em resposta aos procedimentos dolorosos em recém-nascidos pré-termo: uma revisão da literatura. Rev Bras Ter Intensiva. 2011;23(3):370-3.

13. Sá FE, Sá RC, Pinheiro LMF, Callou FEO. Relações interpessoais entre os profissionais e as mães de prematuros da unidade canguru. Rev Bras Promoç Saúde. 2010 abr [acesso em 2015 jun 6];23(2):144-9. Disponível http://www.unifor.br/images/pdfs/rbps/artigo6_2010.2.pdf.

14. Spehar MC, Seidl EMF. Percepções maternas no Método Canguru: contato pele a pele, amamentação e autoeficácia. Psicol Estud [Internet]. 2013 out [acesso em 2015 jun 21];18(4):647-56. Disponível em: http://www.scielo.br/pdf/pe/v18n4/07.pdf.

15. Demari L, Gomes JS, Stucky RMM, Kolankiewicz ACB, Loro MMR, Piovesan CLS. Estratégias para promoção do aleitamento materno em recém-nascidos pré-termo: estudo bibliográfico. Rev Paul Pediatr. 2011;33(2):89-96.

16. Arivabene JC, Tyrrell MAR. Método mãe canguru: vivências maternas e contribuições para a enfermagem. Rev Latinoam Enferm [Internet]. 2010 mar-abr [acesso em 2014 out 21];18(2):262-8. Disponível em: http://www.scielo.br/pdf/rlae/v18n2/pt_18.pdf.

17. Cruz ARM, Oliveira MMC, Cardoso MVLMLC, Lúcio IML. Sentimentos e expectativas da mãe com filho prematuro em ventilação mecânica. Rev Eletrônica Enferm [Internet]. 2010 


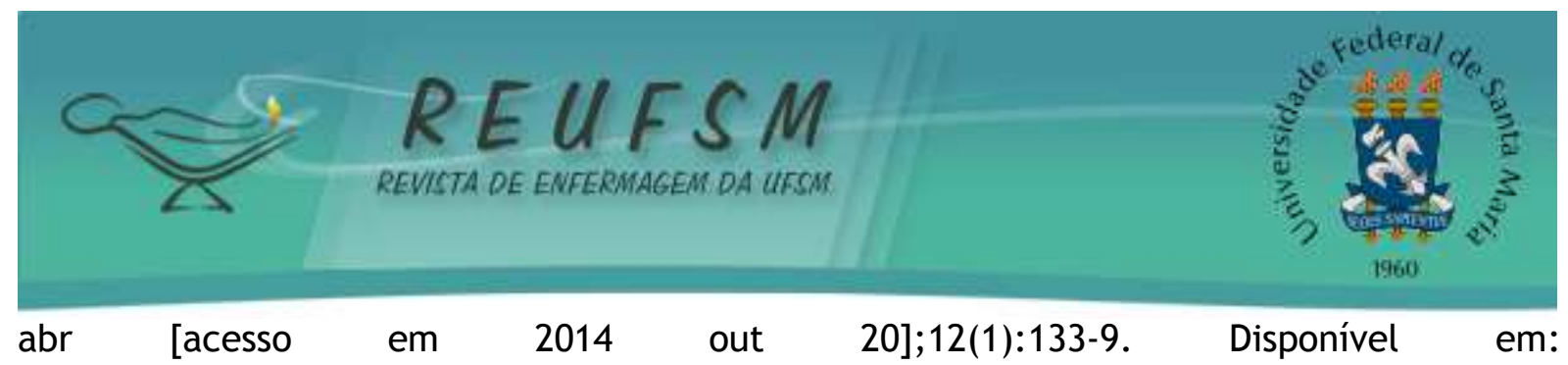
https://www.fen.ufg.br/fen_revista/v12/n1/pdf/v12n1a16.pdf.

18. Gorgulho FR, Rodrigues BMRD. A relação entre enfermeiros, mães e recém-nascidos em unidades de tratamento intensivo neonatal. Rev Enferm UERJ. 2010;18(4):541-6.

19. Frigo J, Zocche DAA, Palavro GL, Turatti LA, Neves ET,Schaefer TM. Percepções de pais de recém-nascidos prematuros em unidade de terapia intensiva neonatal. Rev Enferm UFSM [Internet]. 2015 jan-mar [acesso em 2015 nov 24];5(1):58-68. Disponível em: http://cascavel.ufsm.br/revistas/ojs-2.2.2/index.php/reufsm/article/view/12900/pdf.

20. Melo RCJ, Souza IEO, Paula CC. Enfermagem neonatal: o sentido existencial do cuidado na unidade de terapia intensiva. Rev Bras Enferm. 2013;66(5):656-62.

21. GontijoTL, Xavier CC, Freitas MIF. Avaliação da implantação do Método Canguru por gestores, profissionais e mães de recém-nascidos. Cad Saúde Pública. 2012;28(5):935-44.

22. Veras RM, Traverso-Yepez MA. O cotidiano institucional do Método Mãe Canguru na perspectiva dos profissionais de saúde. P\&S [internet] 2011 nov [acesso em 2015 set 22];23(N Esp):90-8.Disponível

http://www.scielo.br/pdf/psoc/v23nspe/a12v23nspe.pdf.

em:

Data de recebimento: 25/11/2015

Data de aceite: 29/12/2016

Contato do autor responsável: Elaine Cristina Rodrigues Gesteira

Endereço postal: Rua: Sebastião Gonçalves Coelho,400- Bairro Chanadour-Cep: 35501296-

Divinópolis-Minas Gerais

E-mail: ecr.gesteira@hotmail.com 